\title{
Colon Polyp
}

National Cancer Institute

\section{Source}

National Cancer Institute. Colon Polyp. NCI Thesaurus. Code C2954.

A polypoid lesion that arises from the colon and protrudes into the lumen. This group includes adenomatous polyps, serrated polyps, and hamartomatous polyps. 